\title{
NGHIÊN CỨU TỶ LỆ NHIỄM HPV TYP NGUY CƠ CAO Ở BỆNH NHÂN TẠI BỆNH VIỆN TRUNG ƯƠ'NG THÁI NGUYÊN NĂM 2019 -2020
}

\section{TÓM TẮT}

Đặt vấn đề: Human Papillomavirus (HPV) là tác nhân thường gặp nhất trong các nhiễm trùng lây truyền qua đường tình dục. Có hơn 200 genotype HPV khác nhau trong đó tám genotype HPV (HPV-16, -18, $31,-33,-35,-45,-52$, và -58$)$ được thống kê là những genotype phổ biến nhất. vắc xin phòng chống HPV-16 và HPV-18 đã góp phần đáng kể trong việc giảm tỷ lệ UTCTC trên thế giới. Muc tiêu: Xác đinh tỷ lệ nhiếm HPV virus, một số yếu tố liên quan và khảo sát sự phân bố Genotype trên bênh nhân nhiễm HPV tại Bệnh viện Trung ương Thái Nguyên. Phương pháp nghiên cứu: Nghiên cứu mô tả cắt ngang. Kết quả: Trong tổng số 302 bệnh nhân được xét nghiệm HPV có 87 trường hợp bệnh nhân dương tính: trong đó sô bệnh nhân trong nhóm tuổi nhỏ hơn 25 tuổi dương tính HPV chiếm tỷ lệ cao nhất $45,8 \%(p<0,05)$; không có sự khác biệt về giới và địa dư; tất cả bệnh nhân dương tính HPV chưa được tiêm vaccin HPV trước đó. Nhóm bệnh nhân nhiễm 12 typ nguy cơ cao khác type 16, typ 18 chiếm 60,92\%. Kết luận: Nhiễm HPV gây nguy cơ cao trong ung thư đường sinh dục, do đó cân tiêm phòng HPV cho những người dưới 25 tuổi.

Tư khóa: Human papillomavirus, HPV Genotype

\section{SUMMARY}

STUDY ON HIGH RISK TYPE HPV INFECTION

RATE IN THE PATIENT AT THAI NGUYEN

CENTRAL HOSPITAL YEAR 2019 -2020

Human papillomavirus is the most common sexually transmitted infection. There are more than 200 types of HPV have been identified, and about 15 types (HPV-16,-18, -31, -33, -35, -39, -45, -51, -52, $56,-58,-59,-66,-68,-82$ ) have been shown more popular. The bivalent vaccine containing the serotypes 16 and 18 have important rule to reduce the cervical cancer in the world. Objective: To estimated the percentage and some factors which HPV related disease; to indentified the variant of HPV genotype in patients at Thai Nguyen National Hospital. Methods: descriptive cross-sectional study. Results: 87 out of 302 patients were HPV positive; the under 25-age group was accounted for $45.8 \%(p<0.05)$, female were detected for $77.01 \%$; the other high-risk genotype was shown highest in the research. Conclusions: the under 25-age group was essiential vaccinated.

Key words: Human papillomavirus, HPV genotype

*Trường Đại học Y Dược Thái Nguyên Chịu trách nhiệm chính: Bùi Thị Thu Hương Email: huongbuithithu@tnmc.edu.vn Ngày nhận bài: 13.11.2020

Ngày phản biện khoa học: 23.12.2020

Ngày duyệt bài: 4.01.2021
Bùi Thị Thu Hương*, Lò Minh Trọng*

\section{I. ĐĂT VẤN ĐỀ}

Human Papillomavirus (HPV) là tác nhân thường gặp nhất trong các nhiễm trùng lây truyền qua đường tình dục và là nguyên nhân gây ra ung thư cố tử cung (UTCTC), loại ung thư đứng hàng thứ hai trong các loại ung thư ở nữ giới tại các vùng kém phát triển [1].

Cho tới ngày nay đã có hơn 200 genotype HPV khác nhau về vật liệu di truyền, và khoảng 15 type (HPV-16, $-18,-31,-33,-35,-39,-45$, $51,-52,-56,-58,-59 .-66,-68,-82)$ được thấy có liên quan đến UTCTC[1]; trong đó tám genotype HPV (HPV-16, -18, -31, -33, -35, -45, 52 , và -58 ) được thống kê là những genotype phổ biến nhất. Ở nam giới, có $80-90 \%$ ung thư hậu môn và gần $50 \%$ ung thư dương vật có liên quan tới nhiểm HPV. Ở nữ, HPV DNA phổ biến ở $36-40 \%$ ung thư âm hộ và gần $90 \%$ ung thư âm đạo [2].

Hàng năm trên thế giới, ước tính có khoảng 529.000 ca mắc mới UTCTC, tử vong khoảng 275.000 trường hợp, trong đó $85 \%$ tổng số các trường hợp bệnh gặp ở những nước đang phát triển[1]. Tại Việt Nam, theo thống kê của Tổ chức Y tế thế giới năm 2010, UTCTC hiện đang là loại ung thư chiếm tỷ lệ cao nhất ở nữ giới lứa tuổi 15 - 44, với hơn 6000 ca nhiễm mới (tỷ lệ: 11,7 trên 100,000 phụ nữ) và tử vong hơn 3000 trường hợp mỗi năm [7].

Hiện nay, vaccin phòng chống HPV-16 và HPV-18 đã góp phần đáng kể trong việc giảm tỷ lệ UTCTC trên thế giới. Tuy nhiên, khả năng bảo vệ chéo của vắc xin phòng chống HPV-16, -18 được chứng minh là kém hiệu quả hơn đối với các genotype "nguy cơ cao" khác (dưới $1 \%$ )

Với những ý nghĩa trong việc xét nghiệm phát hiện sớm nhiễm virus HPV và xác định Genotype HPV giúp cho việc tiên lượng và điêu trị bệnh, chúng tôi thực hiện đề tài "Xác định tỷ lệ nhiếm HPV typ nguy cơ cao ở bệnh nhân xét nghiệm HPV DNA tại khoa MD-DTPT bệnh viện Trung ướng Thái Nguyên năm 2019 - 2020"với mục tiêu:

1. Xác định tỷ lệ nhiếm HPV virus và một số yếu tố liên quan trên bệnh nhân nhiễm HPV tại Bệnh viện Trung ương Thái Nguyên.

2. Khảo sát sự phân bố Genotype trên bênh nhân nhiễm HPV tại Bệnh viện Trung ương Thái Nguyên. 


\section{II. ĐỐI TƯỢNG VÀ PHƯƠNG PHÁP NGHIÊN CỨU}

2.1. Đối tượng nghiên cứu. Tất cả bệnh nhân đến khám tại khoa Sản, khoa Ngoại tiết niệu, khoa Da liễu và phòng khám Yêu cầu có chỉ định làm xét nghiệm HPV DNA và HPV Genotype tại Bệnh viện Trung ương Thái Nguyên.

*Tiêu chuẩn lựa chon:

- Tất cả bệnh nhân đến khám có tiền sử đã quan hệ tình dục

- Bênh nhân đồng ý tham gia nghiên cứu

*Tiêu chuẩn loại trừ:

- Loại khỏi nghiên cứu các bệnh nhân không đồng ý tham gia nghiên cứu

2.2. Thời gian và địa điểm nghiên cứu

- Thời gian nghiên cứu: Từ 01/01/2019 đến $31 / 08 / 2020$

- Địa điểm nghiên cứu: Khoa Miễn dịch - Di truyền phân tử, Bệnh viện Trung ương Thái Nguyên.

\subsection{Phương pháp nghiên cứu}

- Phương pháp nghiên cứu mô tả

- Thiết kế nghiên cứu: hồi cứu kết hợp tiến cứu

- Cõ mẫu: Chọn mẫu thuận tiện

\subsection{Phương tiện nghiển cứu}

- Thông tin bệnh nhân được ghi lại trên bệnh án nghiên cứu

- Mẫu bệnh phẩm được thu nhận từ phòng khám được xử lý và phân tích kết quả bằng hệ thống Realtime PCR SaCycler 96 hoặc hệ thống Realtime PCR Rotor 5 kênh màu.

\subsection{Các chỉ tiêu nghiên cứu}

- Đăc điểm chung: tuổi, giới, đia dư, tình trạng tiêm vaccine phòng virus HPV

- Kết quả xét nghiệm: HPV dương hay âm tính, typ HPV được ghi nhận theo phiếu kết quả xét nghiệm

2.6. Xử lý số liệu. Số liệu được thu thập theo mẫu bệnh án, lưu trên Excel, xử lý số liệu bằng phần mềm SPSS 20.0

\section{7. Đạo đức trong nghiên cứu}

- Nghiên cứu được thông qua Hội đồng Y đức của Bệnh viện TW Thái Nguyên

- Bệnh nhân đồng ý tham gia vào nghiên cứu.

\section{KẾT QUẢ NGHIÊN CứU}

Bảng 1. Đặc điểm chung của các đối tượng được xét nghiệm HPV

\begin{tabular}{|c|c|c|c|}
\hline \multicolumn{2}{|c|}{ Đặc điếm } & Số bệnh nhân & $\mathbf{\%}$ \\
\hline \multirow{3}{*}{$\begin{array}{c}\text { Nhóm } \\
\text { tuối }\end{array}$} & $\leq 25$ & 72 & 23.8 \\
\cline { 2 - 4 } & $26-35$ & 122 & 40.4 \\
\cline { 2 - 4 } & $\geq 35$ & 108 & 35.8 \\
\cline { 2 - 4 } & Tống & $\mathbf{3 0 2}$ & $\mathbf{1 0 0}$ \\
\hline \multirow{3}{*}{ Giới } & Nữ & 235 & 77.8 \\
\cline { 2 - 4 } & Nam & 67 & 22.2 \\
\cline { 2 - 4 } & Tống & $\mathbf{3 0 2}$ & $\mathbf{1 0 0}$ \\
\hline \multirow{3}{*}{ Địa dư } & Thành thị & 83 & 27.5 \\
\cline { 2 - 4 } & Nông thôn & 219 & 72.5 \\
\cline { 2 - 4 } & Tống & $\mathbf{3 0 2}$ & $\mathbf{1 0 0}$ \\
\hline \multirow{2}{*}{$\begin{array}{c}\text { Tiêm } \\
\text { vaccine }\end{array}$} & Có & 8 & 2.6 \\
\cline { 2 - 4 } HPV & Không & $\mathbf{2 9 4}$ & 97.4 \\
\cline { 2 - 4 } & Tống & $\mathbf{3 0 2}$ & $\mathbf{1 0 0}$ \\
\hline \multirow{2}{*}{ Nhân }
\end{tabular}

Nhận xét: - Số người đến khám và được xét nghiệm HPV nhiều nhất trong độ tuổi từ 26 - 35 tuổi, chiếm $40.4 \%$ và thấp nhât là lứa tuổi dưới 25 với $23.8 \%$

- Số bệnh nhân được xét nghiệm nhiều hơn nữ, lần lượt là $77.8 \%$ và $22.2 \%$

Chỉ có 8 bệnh nhân trong nhóm được xét nghiệm HPV được tiêm vaccin HPV trước

\section{Bảng 2. Tỷ lệ nhiễm HPV}

\begin{tabular}{|c|c|c|}
\hline HPV type & Số lượng & Tỷ lệ \\
\hline Dương tính & 87 & 28.8 \\
\hline Âm tính & 215 & 71.2 \\
\hline Tống & $\mathbf{3 0 2}$ & $\mathbf{1 0 0}$ \\
\hline
\end{tabular}

Nhận xét: Số bệnh nhân được xét nghiệm HPV có kết quả dương tính là 87 , chiếm $28.8 \%$ tổng số bệnh nhân.

Bảng 3. Các yếu tố liên quan đến tỷ lệ nhiễm HPV

\begin{tabular}{|c|c|c|c|c|c|c|}
\hline \multirow{2}{*}{\multicolumn{2}{|c|}{ Đặc điểm }} & \multicolumn{2}{|c|}{ Dương tính } & \multicolumn{2}{|c|}{ Ām tính } & \multirow[b]{2}{*}{ P_value } \\
\hline & & SL & $\%$ & $\mathbf{S L}$ & $\%$ & \\
\hline \multirow{3}{*}{ Nhóm tuổi } & $\leq 25$ & 33 & 45.8 & 39 & 54.2 & \multirow{3}{*}{$<0.05$} \\
\hline & $26-35$ & 31 & 25.4 & 91 & 74.6 & \\
\hline & $\geq 35$ & 23 & 21.3 & 85 & 78.7 & \\
\hline \multirow{2}{*}{ Giới } & Nũ̃ & 67 & 28.5 & 168 & 71.5 & \multirow{2}{*}{$>0.05$} \\
\hline & Nam & 20 & 29.9 & 47 & 70.1 & \\
\hline \multirow[b]{2}{*}{ Địa dư } & Thành thị & 26 & 31.3 & 57 & 68.7 & \multirow{2}{*}{$>0.05$} \\
\hline & Nông thôn & 61 & 27.9 & 158 & 72.1 & \\
\hline \multirow{2}{*}{$\begin{array}{c}\text { Tiêm vaccine } \\
\text { HPV }\end{array}$} & Có & 0 & 0 & 8 & 100 & \multirow{2}{*}{$>0.05$} \\
\hline & Không & 87 & 29.6 & 207 & 70.4 & \\
\hline
\end{tabular}

Nhận xét: Trong số bệnh nhân được xét nghiệm, nhóm tuối dưới 25 có số người dương tính với HPV nhiều nhất là 33 người, chiếm 45.8\%. Sự khác biệt có ý nghĩa thống kê 
Bảng 3. Phân bố các type HPV trong số bênh nhân có kết quả dương tính với HPV

\begin{tabular}{|c|c|c|}
\hline HPV type & Số Lượng & Tỷ lệ \\
\hline Type 16 & 14 & 16.09 \\
\hline Type 18 & 1 & $1 / 87$ \\
\hline 12 type nguy cơ cao khác & 53 & 60.92 \\
\hline Dương tính đồng thời 2 loại & 17 & 19.54 \\
\hline Dương tính cả 3 loại & 2 & $2 / 87$ \\
\hline Tống & $\mathbf{8 7}$ & $\mathbf{1 0 0}$ \\
\hline
\end{tabular}

Nhận xét: Số bệnh nhân có kết quả HPV genotype trong nhóm 12 typ nguy cơ cao khác chiếm tỷ lệ cao nhất là $60.92 \%$; và thấp nhất là typ 18.

\section{BÀN LUẬN}

4.1 Đặc điểm chung của nhóm bệnh nhân được xét nghiệm HPV. Nghiên cứu của chúng tôi được thực hiện trên 302 bệnh nhân. Tất cả các bệnh nhân đều tự nguyện đến khám, được thu thập bệnh phẩm và gửi mẫu thực hiện xét nghiệm tại khoa sinh học phân tử của Bệnh viện. Chúng tôi nhâan thấy số bệnh nhân trong độ tuổi 26 đến 35 tuổi có 122 người, chiếm 40.4\%, nhóm tuổi trên 35 tuổi chiếm $35.8 \%$ lớn hơn nhóm tuổi dưới 25 tuổi được làm xét nghiệm. Kết quả này có thể do số người trong độ tuổi sinh sản và sau độ tuổi sinh sản quan tâm hơn tới tình trạng sức khỏe, thêm vào đó là vấn đề tâm lý khi đến khám chữa bệnh tại các cơ sở y tế.

Tỷ lệ nữ giới chiếm $77.8 \%$ nhiêu hơn nam giới $22.2 \%$.

Tỷ lệ bệnh nhân ở vùng nông thôn trong nghiên cứu được xét nghiệm HPV là $72.5 \%$ cao hơn thành thị $27.5 \%$. Do khu vực nông thôn, thành phố và các khu vực tỉnh khác giáp Bệnh viện Trung ương Thái Nguyên không quá xa, tạo điều kiện tốt cho nhiều người dân được tiếp cận vấn đề chăm sóc sức khỏe tốt hơn.

Tỷ lệ bệnh nhân trong nhóm nghiên cứu được tiêm vaccin HPV là $2.6 \%$. Đây là 1 con số thấp, do vậy cần đẩy mạnh tư vấn, tiêm vaccin phòng HPV trước 25 tuổi và trước khi có quan hệ tình dục. Theo Renjie Wang và cộng sự [3] các vaccin phòng HPV bậc bốn, bậc hai và bậc không có thể giúp phòng nhiễm HPV $90 \%$ tuy nhiên hạn chế loại bỏ các nhiễm HPV trước đó.

4.2 Tỷ lệ nhiễm HPV trong nghiên cứu. Tỷ lệ nhiễm HPV trong nhóm nghiên cứu của chúng tôi là 87 bệnh nhân, chiếm $28.8 \%$ số bệnh nhân được xét nghiệm. Tỷ lệ này của chúng tôi cao hớn so với nghiên cứu của Vũ Văn Tâm và cộng sự (0.976\%)[5] hay Lâm Đức Tâm[6] là $6.64 \%$. Do bệnh phẩm trong nghiên cứu của chúng tôi thu thập trên những bệnh nhân đến khám có và không có tổn thương cổ tử cung; ngoài ra do bệnh nhân của nghiên cứu chúng tôi gồm đối tượng nam giới và nữ giới. Điều này lí giải tỷ lệ HPV trong nghiên cứu của chúng tôi cao hơn. Theo nghiên cứu của David Forman và cộng sự[4] tỷ lệ nhiễm HPV ở phụ nữ không có tổn thương bất thường cổ tử cung cao hơn $11-12 \%$ so với ở Đông Âu (21\%) và Mỹ Latin (16\%).

4.3 Các yếu tố liên quan đến tỷ lệ nhiễm HPV trong nghiên cứu. Trong nghiên cứu của chúng tôi thấy, ở nhóm tuổi dưới 25 số bệnh nhân có kết quả HPV dương tính là 33 người, chiếm $45.8 \%$, sự khác biệt có ý nghĩa thống kê với $p<0.05$; trong nhóm tuổi từ 26 đến 35 có 31 người có kết quả HPV dương tính, chiếm 25.4\%. Số liệu cho thấy tỷ lệ người quan hệ tình dục không an toàn dưới 25 tuổi cao. Theo nghiền cứu của Trần Thanh Tuyền và cộng sự[8] ở 388 sinh viên có $39.9 \%$ quan hệ tình dục trước hôn nhân với tuổi quan hệ lần đầu là 20.9 tuổi, đã quan hệ trên 1 người là $43.9 \%$ và không sử dụng bao cao su là $50.3 \%$. Nghiên cứu của Đố Thị Hạnh Trang và cộng sự['] ] trên 405 sinh viên đại học Nội vụ Hà Nội thây tỷ lệ quan hệ tình dục trước hôn nhân là $23.7 \%$, nam là $30 \%$ và nữ là 20.9\%.Như vậy tình trạng quan hệ tình dục trước hôn nhẩn sớm và không an toàn có thể làm tăng tỷ lệ nhiễm HPV ở lứa tuổi trước 25 tuổi. Số bệnh nhân dương tính HPV từ 35 tuổi trở xuống chiếm tỷ lệ cao hơn với số bệnh nhân được xét nghiệm trong nhóm còn lại. Kết quả này của chúng tôi giống với nghiên cứu của Vũ Văn Tâm và cộng sự [6] trong nhóm tương ứng.

Trong cùng 1 giới, số bệnh nhân nữ có kết quả dương tính với HPV chiếm $29.9 \%$ ( $p>0.05)$. Tỷ lệ này lớn hơn so với nghiên cứu của Lâm Đức Tâm[7] trên 1490 phụ nữ Cần Thơ ghi nhận tỷ lệ nhiễm HPV là 6.64\%; nghiên cứu của Rong Wang và cộng sự[5] trên 120772 phụ nữ ở 37 thành phố của Trung Quốc ghi nhận tỷ lệ nhiếm HPV nguy cơ cao là $21.07 \%$. Sự khác biệt này là do cỡ mẫu của chúng tôi thực hiện còn ít, số lượng bệnh phẩm không nhiều và chỉ ở những bệnh nhẩn đến khám tại bệnh viện được chỉ định xét nghiệm HPV đơn thuần. Trong khi đó, số bệnh nhẩn là nam giới được phát hiện dương tính HPV trong nghiên cứu của chúng tôi là $29.9 \%$. Theo nghiên cứu của Anna R. Giuliano và cộng sự[2] thì có $73 \%$ đàn ông khỏe mạnh được phát hiện nhiễm HPV đường sinh dục.

Có 31.3\% bệnh nhân trong nhóm dương tính HPV sống ở thành thị, trong khi số bệnh nhân này ở nhóm nông thốn là $27,9 \%$, sự khác biệt 
không có ý nghĩa thống kê với $p>0.05$. Trong nghiên cứu của chúng tôi số bệnh nhân có tiền sử tiêm phòng HPV chỉ co 8 người, đều có kết quả âm tính HPV.

4.4 Về phân bố genotype HPV trong nhóm nghiên cứu. Về phân bố tỷ lệ các type trong nhóm dương tính HPV chúng tôi nhận thấy, nhóm bệnh nhân có kết quả dương tính với 1 trong 12 type nguy cơ cao khác chiếm đa số là $60.92 \%$; trong khi số bệnh nhân chỉ dương tính với type 18 chỉ có 1 bệnh nhân. Trong khi đó sô bệnh nhân có kết quả dương tính với cả 2 type nguy cơ cao chiếm phần lớn hơn so với nhiềm đồng thời cả 3 type nguy cơ cao trở lên. Kết quả của chúng tôi giống với nghiên cứu của Vũ Văn Tâm và cộng sự [6]: số bệnh nhân nhiễm 1 trong 12 type là $66.7 \%$, chiếm đa số trong các bệnh nhân có kết quả dương tính.

\section{KẾT LUÂ̂N}

- Số người dưới 25 tuổi có kết quả nhiễm HPV dương tính là 45,8\%. Trong đó các bệnh nhân dương tính HPV dưới 35 tuổi cao hơn nhóm tuổi trên 35 tuổi.

- Không có sự khác biêt có ý nghĩa thống kê về giới và địa dư trong nhóm nghiên cứu.

- Số bệnh nhân nhiễm 1 trong 12 type nguy cơ cao khác type-16 và type 18 cao hơn, chiếm $60,92 \%$.

\section{TÀI LIÊU THAM KHẢO}

1. Manini, E.Montomoli, 2018, "Epidemiology and prevention of Human Papillomavirus", Ann Ig, 30, 28-32

2. Anna R. Giuliano et al, 2008, "Epidemiology of Human Papillomavirus Infection in Men, in Cancers other than Cervical and in Benign Conditions", HHS Public Access, 26, 17-28.

3. Renjie Wang et al, 2020, "Human papillomavirus vaccine against cervical cancer: Opportunity and challenge", Cancer Lett, 471, 88-102.

4. David Forman et al, 2012, "Global burden of human papillomavirus and related diseases", Vaccin, 30, 12-23.

5. Rong WaNG et al, 2015, "Nationwide prevalence of human papillomavirus infection and viral genotype distribution in 37 cities in China", BMC Infect Dis, 15, 257

6. Vũ Văn Tâm và cộng sự, "Nghiên cứu tỷ lệ nhiếm HPV ở bệnh nhân có tổn thương cổ tử cung tại Bệnh viện Phụ Sản hải Phòng bằng kỹ thuật Real-time PĆR và Reverse Dot Blot Hybridization" "

7. Lâm Đức Tâm, 2017, "Nghiên cứu tỷ lệ nhiễm Human Papillomavirus, môtt số yếu tố liên quan và kết quả điêu trị các tốn thương cố tử cung ở phụ nữ thành phố Cần Tho"

8. Trân Thi Thanh Tuyên, Pham Văn Hâu, 2020, "Tình trạng quan hệ tình dục trước hôn nhân và một số yếu tố liên quan của sinh viên một trường cao đẳng tại thành phố Hồ Chí Minh", Tạp chí Y hoc dư phòng, 30.

9. Đố Thị Hạnh Trang và công sự, 2015, "Thực trang quan hệ tình dục trước hôn nhân và một số yểu tố liên quan của sinh viên trường Đại học Nội vụ năm 2015"

\section{RỐI LOẠN ĐIÊ̂N GIẢI, CANXI, MAGIE VÀ PHOSPHO Ở BỆNH NHÂN XO' GAN DO RƯợU}

\section{TÓM TẮT}

Đặt vấn đề: Bệnh gan do rượu bao gồm nhiễm mõ do rượu, viêm gan do rượu và xơ gan do rượu, theo thứ tự tăng mức độ nghiểm trong. Có nhiều biến chứng của bệnh gan do rượu tiến triển, một trong số đó là rối loan chuyển hóa. Muc tiêu: Mô tả sự phổ biến và mối liên quan của rối loạn chất điện giải, chuyển hóa khoáng chất với một số yếu tố ở bệnh nhân xơ gan do rượu. Phương pháp: Nghiên cứu được thực hiên trên 66 bệnh nhân bị xơ gan do rượu (65 nam, 1 nữ;; tuổi trung bình 55,98 \pm 11,25). 6 bệnh

\footnotetext{
${ }^{1}$ Trường Đại học Y Dược Thái Nguyên

²Bênh viện trung ương quân đội 108

Chịu trách nhiệm chính: Đồng Đức Hoàng

Email: Drhoang85@gmail.com

Ngày nhận bài: 13.11.2020

Ngày phản biên khoa họ: 29.12.2020

Ngày duyệt bài: 6.01.2021
}

Đồng Đức Hoàng ${ }^{1}$, Dương Thị Tuyết ${ }^{2}$

nhân thuộc Child $A$, trong khi 30 Child $B$ và 30 Child $C$. Mẫu máu bệnh nhân được thu thập, xét nghiệm và ghi lại kết quả. Kết quả: Hạ natri máu được tìm thấy ở 62,1\% bệnh nhân (tối thiểu, tối đa: 118-141 mmol/L). Tỷ lệ hạ kali máu: 30,3\%, tăng kali máu: 9,1\% (tối thiểu, tối đa: 1,8-5,8 mmol/L). Hạ clo máu là 39,4\%, tăng clo máu: 16,7\%, tối thiểu, tối đa (75-114). Hạ canxi máu rất phổ biến $(75,8 \%)$, tối thiểu, tối đa $(1,34-2,54)$. Có tỷ lệ hạ magie máu cao $(68,2 \%)$, tối thiểu, tối đa $(0,33-1,09)$. Ha phospho máu là $22,7 \%$, tăng phospho máu là $4,5 \%$, tối thiểu, tối đa $(0,40-$ $2,01)$. Trong số các chất điện giải, khoáng chất, $\mathrm{K}^{+}$ (Child A: 4,4 $\pm 0,8$, Child B: 4,1 $\pm 0,8$, Child C: $3,4 \pm$ 0,$7 ; p=0,002$ ) và $\mathrm{Ca}^{++} \mathrm{TP}$ (Child $A: 2,2 \pm 0,1$, Child B: $2,1 \pm 0,2$, Child $C: 1,9 \pm 0,1 ; p=0,01)$ giảm theo mức độ mất bù của xơ gan, các chất khác thay đổi không có ý nghĩa thống kê. Kali huyết thanh trung bình khi không có suy thận là $3,6 \pm 0,7$, tăng khi có suy thận $4.2 \pm 1.1, p<0,05$, các chất khác thay đổi không có ý nghĩa thống kê. Giá trị trung bình của canxi huyết thanh là 2,13 $\pm 0,20$, giảm xuống 2,01 \pm 